\title{
Ebstein's Anomaly with Refractory Right-Side Heart Failure and Leg Ulcers
}

\section{Fei $X u^{1^{*}}$ and Zhong-jiang Zhou ${ }^{2}$}

${ }^{1}$ Department of GI, Sir run run Shaw Hospital, Zhejiang University, Hangzhou, China

${ }^{2}$ Department of Cardiology, Nanfang Hospital, Southern Medical University, Guangzhou, China

*Corresponding author: Fei Xu, Department of GI, Sir Run Run Shaw Hospital, Zhejiang University, Hangzhou, China, Tel: +86 13675865315; E-mail: xufei1025@zju.edu.cn

Rec date: Jan 22, 2015; Acc date: Feb 04, 2015; Pub date: Feb 06, 2015

Copyright: (c) $2015 \mathrm{Xu} \mathrm{F}$, et al. This is an open-access article distributed under the terms of the Creative Commons Attribution License, which permits unrestricted use, distribution, and reproduction in any medium, provided the original author and source are credited.

\begin{abstract}
Ebstein's malformation is a congenital heart disease. The principal pathological change is displacement of the septal leaflet of the tricuspid valve toward the apex of the right ventricle of the heart. The resulting hypoplasia, dysfunction of the right ventricle, and tricuspid regurgitation increase the volume load on the right side of the heart. The clinical features are chest tightness, shortness of breath, fatigue after activity, palpitations, cyanosis, and heart failure. We here report a case of Ebstein's anomaly with refractory right-side heart failure and leg ulcers.
\end{abstract}

Keywords: Ebstein's anomaly; Right-side heart failure; Cardiogenic liver damage; Leg ulcer

\section{Case}

Our male patient was 44 years old and was admitted to hospital for the fifth time since he had been recorded as suffering from "Chest tightness after activity for more than 30 years with abdominal distension, leg edema, and canker 1 year in duration, with an increase in symptom severity commencing 1 month prior".

\section{Physical examination}

The patient appeared chronically ill, with facial swelling, mild scleral jaundice, lip cyanosis, engorgement of the jugular vein, and a reflux-positive liver jugular vein. Lung percussion was voiceless, the breath sounds coarse, and no lung rale was apparent. No precordial bulge was noted; cardiac dullness was significantly expanded to the left; the heart rate was 84 beats/min; arrhythmia was evident; the intensity of the first heart sound differed from that of the others; threeto-six systolic murmurs could be heard in the pulmonary valve auscultation area; and no pericardial friction sound was apparent. Abdominal distension was noted; the abdominal veins; the liver was palpable $2 \mathrm{~cm}$ below the ribs; and the "shifting dullness" test was positive. Severe edema of the lower limbs was noted; skin ulcers 5-8 $\mathrm{cm}$ in diameter were present on the right lower limb, and large purplebrown areas of pigmentation were noted on both lower limbs (Figure $1)$.

\section{Laboratory examination}

Blood test results were not unusual. The white blood cell (WBC) count was $4.58 \mathrm{~g} / \mathrm{L}$, hemoglobin (HGB) $108 \mathrm{~g} / \mathrm{L}$, and platelets (PLT) $109 \mathrm{~g} / \mathrm{L}$. Total bilirubin (TBIL) was $46.4 \mathrm{~m} \mu \mathrm{mol} / \mathrm{L}$, direct bilirubin (DBIL) $25.2 \mathrm{~m} \mu \mathrm{mol} / \mathrm{L}$, and indirect bilirubin (IBIL) $21.2 \mathrm{~m} \mu \mathrm{mol} / \mathrm{L}$. The plasma prothrombin time (PT) was $17.4 \mathrm{~s}$, the part-activated clotting time (APTT) (active enzymes) $39.5 \mathrm{~s}$, and the international standard ratio (PT-INR) 1.45.

\section{Clinical examination}

Chest radiography revealed cardiomegaly, a cardiothoracic ratio of 0.78, and evidence of congenital heart valve disease (Figure 2). Electrocardiography revealed atrial fibrillation (Figure 3), specifically:

- Ebstein's malformation

- An atrial septal defect (secundum, right-to-left shunt)

- Tricuspid regurgitation (severe)

- Mitral regurgitation (severe)

- A normal LVEF; Low-level pericardial effusion (Figure 4).

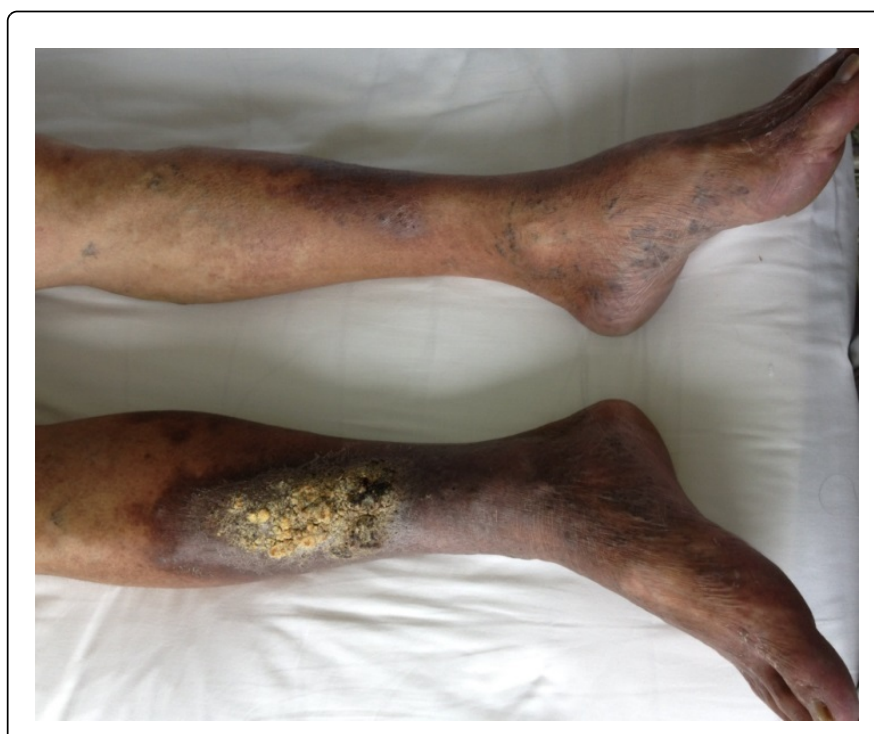

Figure 1: Pigmentation on both lower limbs 
Page 2 of 3

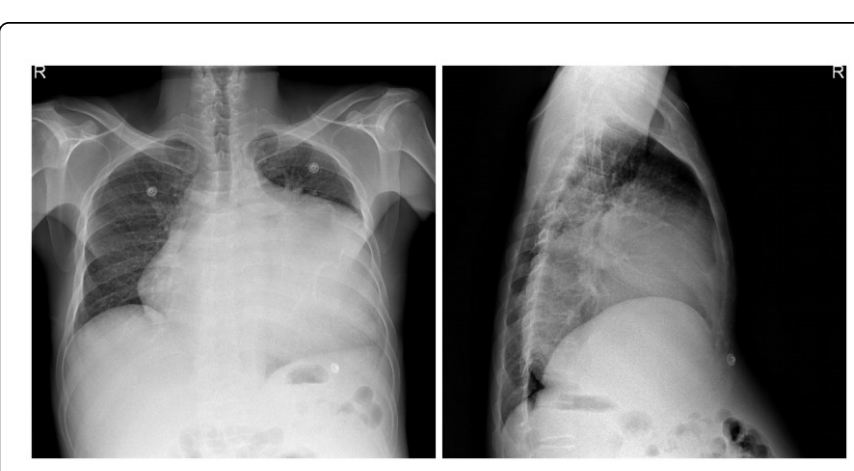

Figure 2: Evidence of congenital heart valve disease

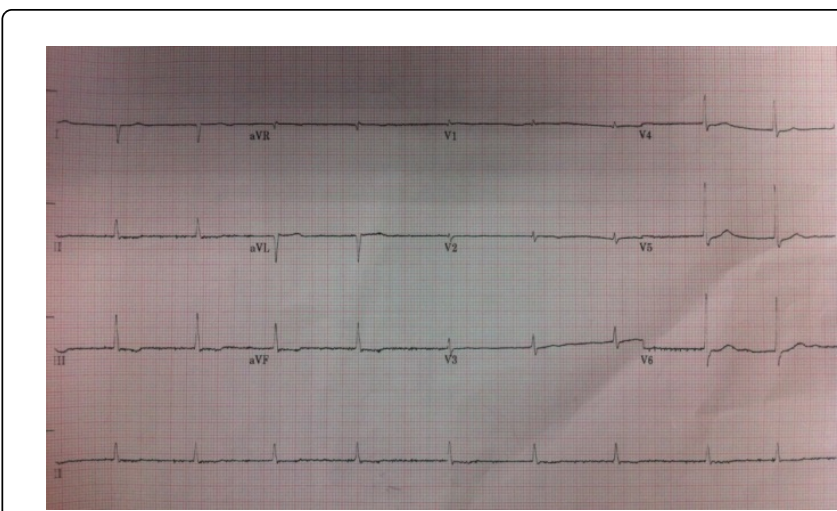

Figure 3: Electrocardiography showing atrial fibrillation
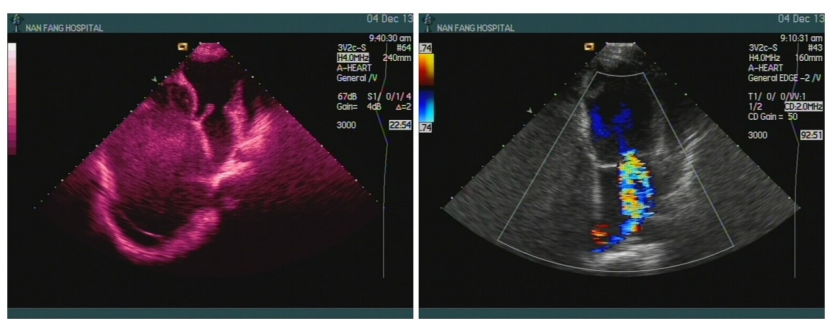

Figure 4: Low-level pericardial effusion

Bilateral lower extremity venous ultrasonography revealed twosided deep venous insufficiency. Abdominal ultrasonography revealed liver parenchymal echo thickening; widening of the hepatic vein, the right hepatic vein, and the inferior vena cava; gallbladder wall edema; and a large celiac effusion.

\section{Diagnosis}

1. Congenital heart disease, with:

- Ebstein's malformation;

- Permanent atrial fibrillation;

- Heart failure; and

- NYHA: Class IV

1. Cardiac cirrhosis
2. Lower-extremity skin ulcers and infections

\section{Management}

The symptoms were treated by prescribing furosemide, spironolactone, trimetazidine dihydrochloride, coenzyme Q10, Essentiale, and Rivanol.

\section{Discussion}

Ebstein's malformation is a congenital heart disease. The principal pathological change is displacement of the septal leaflet of the tricuspid valve toward the apex of the right ventricle of the heart.

Most cases of the malformation are associated with an atrial septal defect or a patent ductus arteriosus. The right ventricle is divided into two regions, of which one is directly associated with the malformation, and functionally integrated with the right atrium. The region not involved in the anomaly can be further subdivided into two parts termed the trabecular and outlet portions. The "atrialized" portion of the right ventricle can become disproportionately dilated and may attain a volume more than half that of the entire right ventricle. Twothirds of hearts with Ebstein's anomaly exhibit dilated right ventricles, including the atrialized inlet portion of the ventricle, but have functional right ventricular apices and outflow tracts. Most cases are associated with (varying degrees of) tricuspid regurgitation. Such functional impairment of the right ventricle, and regurgitation of the tricuspid valve, retard the forward flow of blood through the right side of the heart. In addition, during contraction of the atrium, the atrialized portion of the right ventricle balloons out and acts as a passive reservoir, decreasing the volume of ejected blood. The overall effect on the right atrium is dilatation, increasing the size of interatrial communication. Tricuspid regurgitation is increased by annular dilatation. The heart disease associated with Ebstein's anomaly has further negative effects on patient physiology. The clinical manifestations are cyanosis, right-sided heart failure, arrhythmias, and sudden cardiac death. Patients in all age groups can present with supraventricular tachycardia and some patients suffer from preexcitation syndrome. Diagnosis is based principally on the findings of echocardiography, chest X-rays, and right heart catheterization.

Patients with Ebstein's anomaly and cardiac failure who are not surgical candidates are treated using standard therapies for heart failure, including diuretics and digoxin. The efficacy of inhibitors of angiotensin-converting enzyme I (ACE I) in patients with Ebstein's anomaly and right-sided heart failure remains controversial. Medical management of arrhythmias should be individualized and combined with operative or catheter-based interventions [1], as emphasized by the Canadian Cardiovascular Society (CCS) Consensus Conference guidelines [2] on heart failure.

The CCS recommends surgical intervention if of the following indications are present [2]: A limited exercise capacity (NYHA grade III-IV); an increase in heart size (a cardiothoracic ratio greater than $65 \%$ ); significant cyanosis (a resting oxygen saturation of less than $90 \%)$; severe symptomatic tricuspid valve regurgitation; and a transient ischemic attack or a stroke. The principal surgical procedures are placement of a tricuspid valve prosthesis, tricuspid valve replacement, heart transplantation, and heart-lung transplantation. The prognosis of patients with Ebstein's malformation varies. McElhinney et al. [2] found that, of neonates with Ebstein's anomaly, $20-40 \%$ did not survive for 1 month, and fewer than $50 \%$ survived to 5 years [3]. Celermajer et al. [4] reviewed 220 cases of Ebstein's anomaly, 
Page 3 of 3

with 1-34 years of follow-up. The actuarial survival rate of all live-born patients was $67 \%$ at 1 year and $59 \%$ at 10 years. Predictors of death were the severity of the echocardiographic grade on presentation, fetal presentation, and obstruction of the right ventricular outflow tract. Rarely, patients with Ebstein's anomaly live for over 70 years; one patient died at 85 years of age [5].

Our patient was admitted to our hospital 3 years prior because of chest tightness and shortness of breath. Echocardiography, right-heart catheterization, and chest radiography yielded information allowing us to diagnose Ebstein's malformation. Over the past 3 years, our patient has been repeatedly hospitalized for the above reasons and we have prescribed the symptomatic treatments described above.

Abdominal ultrasound shows that the liver parenchymal echo is thickening over time; the hepatic vein, the right hepatic vein, and the inferior vena cava are widening; and the large celiac effusion is becoming more marked. Patients with long-term right ventricular dysfunction develop circulation stasis, obstruction of the inferior vena cava, elevated hepatic venous pressure, congestion of the central areas of the hepatic lobules, sinusoidal dilatation, hemorrhage, and edema. Thus, the liver becomes enlarged and exhibits local tenderness. Longterm right-side heart failure can cause cardiac cirrhosis. The associated liver cell degeneration and necrosis trigger an elevation in serum aminotransferase levels, and jaundice. The right lower-extremity skin ulcers and infections of our patient were considered to be caused by right-sided heart failure. The chronic right-side ventricular dysfunction renders the peripheral blood flow slow and blocks returning venous blood. As the anterior tibial vascular network is small, any skin damage heals slowly and the skin may become infected easily. The 2013 ACCF/AHA Guidelines for the Management of Heart Failure indicated that our patient was at stage D, thus with refractory right-sided heart failure. Patients at this stage require aggressive control of risk factors; both the pulmonary hypertension and coronary heart disease require attention. Inhibitors of ACE I; and angiotensin receptor blockers (ARBs) and $\beta$-blockers, are currently not recommended, because these drugs may increase pulmonary artery pressure, triggering further heart failure and pulmonary edema. Cardiac and diuretic therapies should be given. Some patients may be surgical candidates, depending on their clinical situation [6-8].
However, our patient had refractory heart failure and his general condition was bad; his EuroSCORE [9] was 7.55\%. We considered that surgery would be too risky. After careful consideration, the patient declined surgery and was prescribed short-term symptomatic treatment with furosemide, spironolactone, trimetazidine dihydrochloride, coenzyme Q10, Essentiale, and Rivanol.

\section{References}

1. Attenhofer Jost CH, Connolly HM, Dearani JA, Edwards WD, Danielson GK (2007) Ebstein's anomaly. Circulation 115: 277-285.

2. Silversides CK, Salehian O, Oechslin E, Schwerzmann M, Vonder Muhll I, et al. (2010) Canadian Cardiovascular Society 2009 Consensus Conference on the management of adults with congenital heart disease: complex congenital cardiac lesions. Can J Cardiol 26: e98-117.

3. McElhinney DB, Salvin JW, Colan SD, Thiagarajan R, Crawford EC, et al. (2005) Improving outcomes in fetuses and neonates with congenital displacement (Ebstein's malformation) or dysplasia of the tricuspid valve. Am J Cardiol 96: 582-586.

4. Celermajer DS, Bull C, Till JA, Cullen S, Vassillikos VP, et al. (1994) Ebstein's anomaly: presentation and outcome from fetus to adult. J Am Coll Cardiol 23: 170-176.

5. Giuliani ER, Fuster V, Brandenburg RO, Mair DD (1979) Ebstein's anomaly: the clinical features and natural history of Ebstein's anomaly of the tricuspid valve. Mayo Clin Proc 54: 163-173.

6. Yancy CW, Jessup M, Bozkurt B, Butler J, Casey DE Jr, et al. (2013) 2013 ACCF/AHA guideline for the management of heart failure: executive summary: a report of the American College of Cardiology Foundation/ American Heart Association Task Force on practice guidelines. Circulation 128: 1810-1852.

7. McMurray JJ, Adamopoulos S, Anker SD, Auricchio A, Böhm M, et al. (2012) ESC guidelines for the diagnosis and treatment of acute and chronic heart failure 2012: The Task Force for the Diagnosis and Treatment of Acute and Chronic Heart Failure 2012 of the European Society of Cardiology. Developed in collaboration with the Heart Failure Association (HFA) of the ESC. Eur J Heart Fail 14: 803-869.

8. European System for Cardiac Operative Risk Evaluation. euroSCORE for doctors page.

9. Poole-Wilson PA, Langer GA (1975) Effect of $\mathrm{pH}$ on ionic exchange and function in rat and rabbit myocardium. Am J Physiol 229: 570-581. 